pÿYoung consumer identity in a restrictive school environment Addictive substances, symbolic goods and consumer skills

\title{
Autio, Minna
}

2016

Autio , M , Lähteenmaa , J , Holmberg , U \& Kujala , J 2016 , ' Young consumer identity in a pÿrestrictive school environment Addictive substances, symbolic goods and consumer skills ' , Children and Youth Services Review , vol. 68 , pp. 100-106 . https://doi.org/10.1016/j.childyouth.2016.07.003

http://hdl.handle.net/10138/173423

https://doi.org/10.1016/j.childyouth.2016.07.003

acceptedVersion

Downloaded from Helda, University of Helsinki institutional repository.

This is an electronic reprint of the original article.

This reprint may differ from the original in pagination and typographic detail.

Please cite the original version. 
Please note that this is a so-called personal version (author's final draft manuscript as accepted for publishing after the review process but prior to final layout and copyediting) of the article: Autio, Minna, Lähteenmaa, Jaana, Holmberg, Ulrika \& Kujala, Jukka (2016) Young Consumer Identity in a Restrictive School Environment - Addictive Substances, Symbolic Goods and Consumer Skills. Children and Youth Services Review 68, 100-106.

\title{
Young Consumer Identity in a Restrictive School Environment - Addictive Substances, Symbolic Goods and Consumer Skills
}

\begin{abstract}
For young people, consuming is an act of constructing identity, where goods, services and styles are important parts of signifying who they are. Our study focuses on young people who are living in restrictive environments, such as special boarding schools. They have been placed there because of social and educational reasons. Although aspects of education and health of young people in out-of-home care have been studied, their consumer behavior has been given limited attention. Our study shows that young people openly report the use of addictive substances such as cigarettes, alcohol, drugs as well as gambling. They also build up their consumer identity by appreciating symbolic goods, such as clothes, music and sport. Spending on expensive clothes serves their favorable self-image. The fact that the schools provide all their essential needs makes the learning of consumer skills challenging although the schools reinforce management skills such as planning the use of money. Young people struggle with their identities at the borders of their school environment (i.e. education, school discipline) and the temptations of consumer culture. Even if they manage to break their damaging life path, they will be consumers throughout their life, meaning their consumer skills need to be strengthened by special education.
\end{abstract}

Keywords: young consumer, identity, school, reform school, restrictive environment, out-ofhome care, special education

\section{Introduction}

When I was a 9 or 10-year-old schoolboy, I started delivering advertisements after school on Wednesdays and Mondays. With the money, they paid me I would buy comic books and ice hockey cards. At about age 12 I started selling World Wildlife Fund pins and other items [...] I would usually spend the money straight away on sweets, slot machines, cigarettes and junk food. Between the ages of 13 to 16, I spent all of my money on drugs or other narcotics. I got the money for my daily narcotics by either stealing it or by selling stolen goods or drugs. - 17-year-old male

This individual gives us one version of the life path of a young man unable to fit into the norms of society, and he sells, trades and steals to fund his addictive lifestyle. The story also includes the tale of a boy entrepreneur who funded his expenditures. He is not on his way to becoming a legal entrepreneur, instead he makes money selling stolen goods and drugs. This young man's development as a consumer has followed the norm up till puberty, when drugs began to consume his money, leading to stealing and increasing marginalization. The young man speaks of his consumer habits and the self-destructive phase of his life in the past tense, as the story 
was written at a residential institution (i.e. reform school), where he has been placed in accordance with the Child Welfare Act.

In order to prevent the increasing marginalization of young people in many countries children are placed in special institutions, such as foster care, municipal children's and juvenile homes (Thompson et al., 2016; Nybell, 2013; Hyde \& Kammerer, 2009; Jahnukainen, 2007; Jones \& Lansdverk, 2006; Barber \& Delfabbro, 2005; Bryderup, 2004) or special boarding schools (Terpstra, 2006). Although young people rarely consider their placement in residential institutions to be necessary, the intervention may halt a damaging cycle in their life paths and at the same time provide them with life management skills (Barber \& Delfabbro, 2005; Jones \& Landswerk, 2006), which presumably includes their expenditure as well. As Ridge (2011, p. 80) has noted, these schools are some of the services that have the potential to make a significant contribution to the well-being of children experiencing problematic life situations. As Skattebol (2011, p. 529) has pointed out disadvantaged young people are at greater risk of not having money management skills. As we can read in the young man's consumer narrative quoted above, his life was based on the illegal economy with a rather 'wasteful' and addictive (e.g. drugs) consumer behavior.

Several studies have shown that young people compensate for low-income (poor), ethnic, and/or difficult life situations by consuming (or stealing) designer clothes and iconic branded goods (e.g. Skattebol, 2011; Ridge, 2011; Diversi, 2006; De Castro, 2006; Nayak, 2006; Elliott \& Leonard, 2004). According to Ridge (2011, p. 75) 'not having enough money' creates considerable material, social and familial tensions for children. Yet, as Gianneschi (2012) has pointed out, also middle class young consumers negotiate and compensate for any limiting aspects of their life situations by making use of symbolic artefacts in consumer culture. Thus, it can be argued that it is not unusual for young people to have problems and tensions in their life, which they solve by consuming. Also Miles et al. (1998) points out that through everyday experience young people constantly seek the stability that social structures can offer them. Thus, they grow up to become economic agents and acting as a consumer is one of the key positions of today's youth, where consumer skills play an important role when young people are coping with tensions in their lives.

Although aspects of education (poor educational outcomes), health (mental care) and reintegration (counselling services) of young people in out-of-home care have been studied (e.g. Thompson et al., 2016; Geiger et al., 2014; Trout \& Epstein, 2010), their consumer behavior and growing up as consumers have been given limited attention. Thus, we are examining the identity work of young consumers in out-of-home placement (i.e. reform schools) in a Nordic country, Finland. It is important to have some insight into how these young people understand themselves as consumers in order to strengthen their life management skills and develop supportive services and mentoring for them in future (Trout \& Epstein, 2010; Thompson et al., 2016). The position of being a consumer is lifelong. Even if they manage to break the habits of using drugs and they find a place in work and family life, they still need to strengthen their skills to be competent actors in contemporary consumer culture.

This article is structured as follows. In section two we discuss consumption as an arena to construct identity and how it reflects the consumer habits of young people in restrictive environments. In section three we present data, the research question and a method for analysis. In section four we build up our arguments based on empirical data obtained by close reading. 
Finally we present our conclusion and reflections of the narrative method as a tool to promote consumer self-comprehension.

\section{Young People's Consumption and Living in Restrictive Environments}

\subsection{Consuming as a Tool for Identity Work}

Branded goods and services are seen as constitutive elements of young people's lives in postindustrial Westerns cultures. Young people are surrounded by commercial products, which are made and marketed especially for them (Nayak \& Kehily, 2013). Thus, the marketplace has a fundamental influence on their everyday life experiences (Miles et al., 1998). In late modern societies youth culture symbolizes enjoyable consuming and leisure time, and young people's lives are often depicted in terms of playing with identities (Featherstone, 1991) where consumption is seen a fundamental arena for identity work. According to Giddens (1991, p. 198) identity work means that the project of the self becomes translated into one of the possession of desired goods and the pursuit of artificially framed styles of life.

Both traditional and (post)modern theories claim that people try to symbolize certain groupidentities by consuming and at the same time distance themselves from others through their consumption and visible lifestyles (e.g. Bourdieu, 1984[2010]); Featherstone, 1991; Slater 2003). Thus, consumers differentiate themselves from others (e.g. group, class) and at the same time assimilate themselves into their own reference group and its norms by consuming (Bourdieu, 1984[2010]; Simmel, 1900[1982]). This behavior has been seen to be distinctive for young consumers and it is also known as peer group pressure (Elliott \& Leonard, 2004). As Miles et al. (1998) have pointed out, young people establish reference groups, which provide a 'sounding board' for ideas and personal meanings.

The presupposition that people do identity work or construct their identities by consuming is discussed in relation to young people's consumption (e.g. Wilska, 2003; Lundby, 2012; Gianneschi, 2012). For example, the action of young people choosing or using certain brands is interpreted as their practicing identity work (Gianneschi, 2012). Yet, there is also consumption, with which people - neither young nor adults - do not make distinctions. For example, when consuming in special circumstances, like in prison by prisoners and in the army by soldiers, consumption serves other functions than distinction. These kinds of consumption activities can be interpreted as symbolic escape from rules and discipline and thus, resisting institutionalization. As Godderis (2006, p. 255) argues prisoners use consumptive spaces to negotiate and contest the power inequalities resulting from the prison's highly regulated environment. Also so-called comfort-eating (e.g. chocolate, junk food), which are not healthy practices have been interpreted, not as identity construction, but 'identity maintenance', when it takes place in prison (Smith, 2002). According to Godderis (2006), consuming (food) in prison acts as a site of contention where struggles over power and identity (de)construction and maintenance can be played out.

Behaving in an addictive way might be seen as a 'refusal to be obedient' to the norms or ideals of rationality and moderation; for example, eating-practices in prison have been interpreted as such (see Godderis, 2006; Smith, 2002). These kinds of refusal are not necessarily reflective and addictions typically serve regressive impulses, and the axis regression-progression could surely be seen in relation to identity work. Reith (2004) pictures addictive consumption: "Rather than consuming to realize the self, in the state of addiction, the individual is consumed 
by consumption; the self-destroyed." Yet, Gilbert (2007) has pointed out that for young people deciding to smoke is related to identity formation, which at least serves identity formation in the beginning and may later develop into addiction.

\subsection{Problematic Behavior and Consuming in Restrictive School Environments}

As noted, children and youths under the age of 18 are placed in residential institutions because social and educational reasons (Jahnukainen, 2007). In other words, either the circumstances they are in, or their own behavior (e.g. being aggressive, out of control, antisocial behavior, see McCrystal et al., 2007), is endangering their healthy development. Other reasons for placement may include a lack of success at school, learning difficulties and an inability to adapt to normal school education. Thus, these residential institutions are specialized in working with young people whose behaviors are considered to be generally inappropriate and problematic. As Jahnukainen (2007, p. 638) has pointed out, institutional care is often labelled as a last-resort intervention: it is used when no other options are available. In other words, if individuals are unable to control themselves, then institutions will do it for them (Reith, 2004, p. 290).

Interpreting consumption as distinctive identity work (Giddens, 1991; Miles, 2000; Gianneschi, 2012) and identity (de)construction is controversial if we think about the behavior of young consumers in a restrictive institution, such as a reform school. Young people are living in relative isolation, where their growing up into (reflective) consumers is challenging because of their circumstances and backgrounds. They might be lacking healthy parental supervision (Trout \& Epstein, 2010; Terpstra, 2006; Barber \& Delfabbro, 2005; Jahnukainen, 2007), and their economic, social and cultural resources (Bourdieu, 1998[2010]) are not necessarily at the same level as 'ordinary' young people (Skattebol, 2011). In addition, young people in reform schools are alienated from ordinary consumer society because they are not freely allowed to spend their free time and money with their peers and in their home environments (i.e. private spaces).

As argued, reform school students have usually had a rather self-destructive way of living, which is also seen in their consuming habits. Drugs, alcohol as well as gambling are all signs of a lack of life management skills, and these people are struggling with these habits (Hyde \& Kammerer, 2009). Even though residential students' money management has traditionally been seen as 'sell, trade, steal' types of activities (Vehkalahti, 2003, p. 16-17), it can nevertheless be approached in the same way as we approach so-called normal or 'ordinary' youth's spending habits, as the bases for the young offenders' placements have become more varied and many of them live less separated from their peers.

Reform schools for children and young people are 'homes' where they live during the placement time, away from their parents. In Finland, reform schools are situated in the countryside, away from the goods and services offered by consumer society (except for eservices). The rural environment aims to dissociate the youth from the circumstances, such as friends or home, which have led to their unfortunate development. Yet, the reform schools are not (mere) punishment institutions. The young people there have more freedom than those confined, for example, in prisons (e.g. Godderis, 2006). They have weekend holidays, certain freedoms to do their hobbies, sometimes also the possibility to make their own food in their own kitchens, etc. However, the young people have limited possibilities for consumption in these schools, as they live in relative isolation. 
Moving to a reform school affects their expenditure, as external control increases and, at the same time, the process of building self-control as a consumer is interrupted. Thus, the schools provide a surrounding where pupils do not necessarily need money for their private use. The students' possibilities for spending are based on a monthly allowance. Their legal guardians and relatives also give them money. Additionally, the monthly sum of available money may be increased by work, paid by the hour, done by the pupils in and outside the schools. Part-time work outside the schools may include working at petrol stations, in local supermarkets or on farms. The reform school property may also include a farm, where the students can develop husbandry skills.

\section{Research Question, Empirical Data and Method}

This study examines young consumers in vulnerable life situations and the study can be included in the vein of youth research, where the focus on the transition from school to ordinary life and towards adulthood (Jahnukainen, 2007; Cunningham \& Diversi, 2013; Gianneschi 2012; Thompson et al., 2016). The theoretical framework is based on the one hand on the sociological discussion of identity work and identity maintenance in the context of consuming (e.g. Featherstone, 1991, Godderis, 2006) and on the other hand on youth studies focusing on young peoples' consuming habits (e.g. Miles et al., 1998, Wilska, 2003, Nayak \& Kehily, 2013) and especially in vulnerable life situations (e.g. Ridge, 2011; Skattebol, 2011). We ask: How do young people who are living in relative isolation picture themselves as consumers in school and in consumer culture? We explore this question by examining narratives written by reform school students in Finland. As Jahnukainen (2007, p. 639) has pointed out it is important to capture stories told by the reform school students themselves - 'giving them a voice' (also Nybell, 2013; Cunningham \& Diversi, 2013).

According to Aaltonen and Honkatukia (2012) institutional settings affect the ways in which young people present themselves in interviews. Despite our - youth researchers' - good intentions, it is difficult to break the formal structure of an interview and thus avoid reproducing relations of authority. Thus, writing essays anonymously was chosen as a better way to gather data from young people in institutional settings than face-to-face interviews. Difficult emotions and 'representations of the self' are not confused when writing essays. Thus, we asked students to write short essays on their consumer behavior with the following guidelines:

Life story as a consumer. Think about your life and growing up to be a consumer from your childhood up to now. What kind of a consumer are you? Which items and services are important to you? What kinds of expenditure or consumption give you the most pleasure or regret?

The narratives reflect the students' life histories as consumers (Bringewatt, 2013) and organize their life experiences (Czarniawska, 2006). The narrative approach is useful when analyzing what kinds of ideas and thought patterns they have and how young people understand their consuming habits (e.g. Autio et al., 2009). For many reform school students, however, writing is an unfamiliar mode of communication, and it may pose difficulties to these young people, even to those who have spent years in basic education. Despite this, they were keen to explore the subject and to write about consumer behavior. Producing a story and relating one's own message to the researchers was the priority, rather than writing a grammatically correct essay.

The research material was gathered in four reform schools in Finland. The informants are 1317 -year-old students, representing the 7 th to 9 th grades of Finnish basic education. The students 
were advised to write a complete story with a clear beginning and a conclusive ending. They wrote their stories during school time, and not in their free time. The empirical material comprises 66 texts, 35 of which were written by girls and 31 by boys (Table 1). The students were told that their texts are to be used for scientific purposes. They were allowed to write anonymously, but they were asked to give their sex, age and school grade. Information affecting identification of individuals has been eliminated from the text according to the instructions given by the Finnish Department of Health and Social Services. Each quote contains the informant's gender, school grade and/or age and their consumer description if mentioned. The texts written by these young people vary from a few lines to complex compositions. The stories are mainly between 100-200 words, but they also wrote some 400 -word texts.

As Mary Douglas (1966 [2002]) has pointed out, cultural life is in constant tension between control and resistance, orders and disorders. Thus, we first looked for what young people wrote about their consuming items (content analysis, Table 1), what kinds of symbolic goods and boundaries they create in their stories, and how they described staying at school (restrictive environment). In Table 1 we present the first analysis of the written stories. For girls beauty care and clothes were more important than to boys, who valued games and mobile phones more.

Table 1 . The most mentioned consumer goods in the young people's narratives $(\%)$

\begin{tabular}{lcc}
\hline Consumer goods & $\begin{array}{l}\text { Girls } \\
(\mathrm{n}=35)\end{array}$ & $\begin{array}{l}\text { Boys } \\
(\mathrm{n}=31)\end{array}$ \\
Cigarettes & 40 & 36 \\
Sweets & 22 & 10 \\
Alcohol & 20 & 16 \\
& & \\
Games & 9 & 48 \\
Mobile phone & 17 & 32 \\
Beauty care & 40 & 3 \\
Music & 20 & 10 \\
Clothing & 54 & 16 \\
\hline
\end{tabular}

We understood that symbolic artefacts such as expensive clothes and games (e.g. PlayStation) were present in the stories and they wrote openly about their addictive behavior. Thus, we were analyzing narratives by looking at 'addictive' (Reith, 2004) and reflective 'identity-seeking' (Giddens, 1991; Gianneschi, 2012) behaviors. After that we looked at how they viewed their consumer behavior during their time in reform school and how they described the (possible) changes in their consumption at school. Then we turned to use a method of close reading where we picked up stories (Moisander \& Valtonen, 2006) which reflect our findings (addictive behavior, identity maintenance and identity work, life at school) and analyzed those in detail. We also figured out that vulnerable young people strive for 'normality' appreciating branded goods and picturing a controlled use of money. It is notable that we are not only focusing on the problematic behavior of these young people, but instead, we are picturing them as capable agents of the consumer society. 


\section{Findings}

\subsection{Addictive Substances and Identity Maintenance - Fags and Snacks}

As noted, we were interpreting young people's consumer stories as addictive or identity maintenance points of view (Reith, 2004; Godderis, 2006). We first looked at the non-reflective side of identity work and we identified rather laconic descriptions of their spending. They wrote almost pure 'lists' of the objects what they consumed or bought. However, already from the plain lists of the things, which are consumed, we can identify addiction and find maintenance rather than reflective consumer behavior. A boy and a girl comment on their consuming lists thus:

When I was a child, I hardly spent at all. Now it all goes and disappears in the blink of an eye. I smoke, quite a bit. Items and things important to me are my guitar, clothes. Home, friends and cigarettes. Smoking and phones. - 15-year-old boy

I have spent all my money on sweets, all. I began to buy cigarettes in the third grade (10 years). I am able to save money, which is, in fact, difficult. I spend all my money on music, make-up, perfumes, clothes and white chocolate. - 13-year-old girl

The boy mentioned smoking three times in his short story. He also said that home and friends were important, which indicates that consuming includes more than just goods and services. The girl's consumer history from childhood has developed from instant gratification (sweets, cigarettes) towards typical youth purchases (music, make-up, perfumes, clothes). The most frequently mentioned consumer goods in the stories are slot machines, alcohol, cigarettes, and sweets (Table 1), and all these at least can be, and often are, consumed addictively. As a girl tells us in her story:

My money's often spent on make-up, cigarettes, and clothes and on days off, spirits and beers. Maybe I'll learn to manage money when I get older. - 15-year-old girl

This kind of consuming sweets and/or junk food addictively is not constructing consuming style as such. As Fiates, Amboni and Teixeira (2008) have pointed out, primary school children use their money mainly on food (i.e. salted snacks, candies, gum, lollipops, ice cream), toys and clothes. Thus, sweets and snacks are distinctive consuming items for children, which do not serve identity work as clothes and music do for young consumers. However, our informants also wrote stories, which are at the same time reflected and explicit as well as unreflected. A boy tells us his story about addictive consumption at home and in reform school:

When I then went to secondary school, I began to smoke cigarettes and drink alcohol. I always got money from my parents. When I first got into an institution [i.e. reform school] I began to get a monthly allowance. It all went to cigarettes and alcohol. - 13year-old boy

Some of the descriptions of past or current addiction problems are rather explicit. A boy tells about his present consumer behavior:

When I was 12 my gambling addiction begun, and I spent all my money on slot machines. In addition, if I won, I played them again. Now I am rather moderate with money, 
spending on clothes and some other things. Clothes and food are important to me. ... I do not get satisfaction from spending money, instead I become frustrated when I buy useless things. Of course, buying food and clothes makes me feel great. -15 -year-old boy -

This boy confesses his gambling addiction openly. It seems that he has overcome his problematic behavior, and turned to 'reasonable' consumption. Thus, we can interpret his progress as a success story of 'from addiction towards a sensible reflective agent'. It is difficult to claim that he has distinctively constructed his identity on consuming. Rather he declares that food and clothes are important to him.

In adult consumer culture food (e.g. fine dining), drinks (e.g. luxury wines and whiskies), tobacco (e.g. fine cigars), drugs (e.g. recreational drug use) and gambling (e.g. casinos) can be interpreted as identity work or even part of luxurious lifestyles. However, young people's use of stimulants (addictive substances) is often seen as a problematic behavior. Yet, according to Wilska (2003, p. 441) hedonism, visibility, and open-mindedness have been seen as characteristics of young people's consumption - mainly reserved for ordinary young people. Also careless spending is seen to be typical for young consumers. Thus, reform school students are practicing the 'normal' characteristics of present day youth consumer behavior (e.g. instant gratification, hedonism, spending). However, at the same time they are also expected - as are youth in general - to grow-up as rational agents who are able to control their needs and wants. This part of the identity work is harsh for them due the lack of self-management skills, living instability and the addictive elements of their consumer behavior.

\subsection{Identity Work and Symbolic Goods - Music, Branded Clothes and Games}

Although it is complicated to analyze the characteristics of consumption styles in narratives, traces of identity work are present in the stories. They describe not only just the things they consumed, but also the meanings connected to them. They value fine and expensive clothes, which seems to be an essential part of reform school culture and thus an indication of peer pressure (Elliott \& Leonard, 2004). Consumer durables, such as clothes, PlayStations and make-up are the ways to construct their consumer identity in comparison to consumer goods, such as (junk) food, drinks, tobacco, drugs and gambling. Girls and boys describe consumer durables as: "I love beautiful clothes" or "Music instruments are important to me". These expressions portray the meanings connected to those goods which construct consumer identity. The storylines may also portray self-reflection when students are expressing their will to change their consumer behavior, for example, from 'a squanderer to a prudent actor':

Ever since I was a child, my mother has bought me just about everything I have set my eyes on in a shop. Whenever I got money I would buy something, I would never save up. I'm a really bad consumer, when I get money I buy what I want if I've got enough money, and if not I'll ask my mother for more money so I can get the things or the clothes I want. The last thing I bought was a suit $[\ldots]$. Things that are important to me are things that are useful like PlayStation games and all the expensive items, such as nice clothes. When I buy something, I feel like I have made a sensible purchase. Then when I buy a PlayStation game and get bored with it, I feel like it was a bad purchase. Now I have learnt to save money... I get money every month at school, and I save all of it. Not bad. - 15-year-old boy

The story identifies developing control and evaluating the usefulness of purchases, which makes the writer satisfied, although he also defines himself as a bad consumer for being so 
wasteful. According to Autio (2005), Finnish young people appreciate self-image, which is based on the virtuous consumer, who is a prudent, reasonable agent in control of his/her emotions (also Wilska, 2003). The boy describes the non-virtuous agency: a youngster who is constantly buying things and acting on impulse. Although young consumers have been seen as raving hedonists (e.g. Miles, 2000), they recognize the cultural story of the reasonable and selfcontrolling consumer (Wilska, 2003; Autio, 2005) and they reach out for it.

Yet, students' stories speak of the appreciation of brand clothing. Expensive brand items are day-to-day realities for young people, so developing one's identity through consumption is not a phenomenon related to reform school students alone, but a reflection of the customs of youth culture and the overall Western consumer culture (e.g. Croghan et al., 2006; Gianneschi, 2012). A boy states:

For me important things are useful things such as PlayStation games as well as all fine and expensive clothes. Always when I buy something I get the feeling that: 'Now I have bought something very useful'. - A 16-years-old boy

The appreciation for brand and/or expensive clothing among the marginalized youth may however be based on the idea of lifting one's self-esteem. Compensating for poor backgrounds, vulnerable life situations and problematic life paths is carried out by available means, and clothing is likely to be among the easiest. For example, De Castro (2006, p. 183) in the Brazilian context argues that poor youth spend more money on clothes because 'good looks' are important for showing off a favorable self-image. Also Diversi (2006, p. 386-387) studying street kids found out that iconic brands, like Nike, are a symbol or gateway to 'normality'. Desiring and dreaming of branded clothes makes, according to Diversi, these kids look for the same things we all are longing for, i.e., acceptance, acknowledgement, respect, and self-worth (see also the Australian study, Skattebol 2011, p. 532). Also Elliott and Leonard (2004, p. 349) have noticed in the British context that the possession of branded goods may be an aspect of 'symbolic self-completion' where individuals who perceive themselves as lacking in personal qualities attempt to fill the gap using symbolic resources.

Reform school students are living under control with limited opportunities and means to consume. The appreciation for quality products speaks of a desire to be part of society's norm, to look good and to be successful (Elliott \& Leonard, 2004). They struggle with their consumer behavior in the borderline of wastefulness, a show-off culture and self-management. Their earlier lives have been challenging and now the school environment wants to provide them with life management skills and guide them towards the norms of society. Miles (2000) argues that consumption represents an arena within which young people play out and negotiate their relationship and agency with consumer society (also Gianneschi, 2012). For reform school students this agency, according to rules of society, is not easily available. It seems that either they negotiate themselves as outsiders in society or they strive for 'normality' by consuming branded clothes etc.

\subsection{Struggled Identity: Providing Livelihood and Control over Consuming}

The students were not keen to write about the school environment, neither their placement nor their consumer behavior at school. It is noteworthy that reform schools are places where control is imposed by the staff, regular bedtimes, hobbies and the school routine - not by the young person learning to manage time and money independently. The schools also provides basic 
living expenses and gives the students monthly allowances for work at school or outside school (gas stations, farms etc.). Thus, students have money for consuming provided by the school. They have to manage this life situation, whether to use money or not, where and how. A boy describes the interplay between his consumer habits and the school environment:

[...] When I got to the reform school, it was hard getting used to not having any money because before you could always get some from somewhere. These days I have noticed what useless stuff I used to waste my money on. I might buy an expensive pair of shoes and a skateboard just like that. When I started using alcohol, I noticed that weekends were costly for me. The money I made from my first summer job I spent paying fines. Nowadays I have learnt to save up and I have spent large sums of money on one game and a hi-fi. I do not get phone bills because I am on pay-as-you-go and phone calls are free here. Work is quite good for pocket money; I have started saving up for my own computer and a snowboard. So I have ranked myself as an average consumer because I spend some but I can be thrifty too when I need to. -16-year-old boy -

When the boy was outside the school, he could spend money on free time activities and clothing. Within the school, his expenditures have found their limits: he has understood how the 'luxurious lifestyle', he had been accustomed to, could lead to difficulties in the end. He aims to be more a prudent type of consumer characterized by controlling his mobile phone bills with a pay-as-you-go contract and general thriftiness. Growing to be more responsible can also be seen in his paying his fines - something that cost him his first earnings from a summer job. $\mathrm{He}$ also says that 'phone calls are free here', signifying that the school is providing free services. At the same time this practice increases the freedom to spend his own money and yet, makes difficulties to reach independent agency. Also the girl below illustrates the struggle between autonomy of personal belongings and the things the school provides:

[...] I spend just about all the money I get. I buy cigarettes, jewelry, clothes and other cool things. Therefore, I am a spender.... These days I do not get much money for myself, because my spending is regulated. They give me money for my time off, and I usually spend that quite fast. I buy hygiene products with my own money, which some adults think is wasteful, because the school provides free hygiene products. However, I think it is just a sign of independence! - Girl

The girl constructs her own personal space through hygiene products, which to her also signifies personal autonomy over her choices. Her consuming can be interpreted as a symbolic escape from the rules of school (i.e. free products), and thus resisting institutionalization (Godderis, 2006). She says: My spending is regulated. Unlike addictive consumption (e.g. drugs, alcohol), a hygiene product represents a controllable and independent consumption item for the girl. Furthermore, the product symbolizes a tool to negotiate and contest the power inequalities between the student and school staff in the regulated environment (Godderis, 2006, p. 5). The girl's story also illustrates how difficult it is for a young person to balance his/her own expenditure because the schools provide free materials and services.

The students' consumer behavior is built in two different environments - at school and away from school. Consumption is organized and controlled while the institution guides it. When a student does a runner (unauthorized days off) s/he gets out of control, and often the consequences of this (crime, spending, excessive behavior) follow. This type of behavior is found at all restrictive institutions, such as prison or the military. On the other hand, all young 
people have to develop control of their expenditure as they leave their childhood home, which is not necessarily either easy or self-evident. Even though the students' consumer behaviors develop towards more responsible agency in the institution, the school may have unfavorable aspects such as the effect of peer groups (i.e. brand-focus consumption), as shown in the story below:

I was a flake about 3.5 years ago. I lived with my mom, brother and sister. We did not have much food or clothes. My mom could not take care of us; my sister and me were placed in a school home [i.e. reform school]. My sister spends and squanders a lot; I was a stingy kid I hardly bought anything. After I was placed in the school home I started wasting money, I bought a lot of brand clothes, games and shoes. I have learnt to save the money we get about monthly. I save about $50 \%$ of the money. I usually save up for holidays so I get fags, sweets and games. I worked at various jobs too, so I got money for the summer. I did a lot of washing up and I did the buffet. I like to spend money on sweets and fizzy pops so I am a spender. Sometimes I overdo it, and spend too much. - 16-year-old boy -

The young man describes himself as a flake, who has grown into a young person who works and has control of his expenditure. As a child, he was thrifty, but when he was institutionalized, he learnt the spending habits of a reform school youngster - squandering. He would buy brand clothing, games and shoes. Now he is constructing his behavior in both wasteful and prudent ways. According to Campbell (1987) modern consumption is not just traditional hedonism that aims for instant gratification. Control and suppressing one's desires can also be the source of significant gratification, for example, when the quoted boys are saving up for a new skateboard or holidays. Young people's consumption and expenditure are mostly a continuous battle between self-control and giving in to gratification. However, the consumption habits of reform school students often lack the development of self-discipline, which is also partially due to their young age.

\section{Conclusion}

\subsection{Consumer Identity Work at and away from School}

Young people have written about their consumer behavior during the time they spent in reform schools. Their transition from childhood towards adulthood has not gone by the routes that are considered mainstream or normal. They tend to have broken and unstable backgrounds and their educational past often contain missing episodes. Thus, the young people studied are living in vulnerable conditions, and often their backgrounds as consumers are controversial. Their growing up to be self-controlled consumers usually lacks parental supervision (Terpstra, 2006; Barber \& Delfabbro, 2005), and the school has taken on the task of 'parenting', meaning that the institution at least partially regulates and organizes their expenditure and path of growing up to be responsible consumers. However, placement at a school is just one period of their lives and the institution is only a temporary solution for them.

The challenging life situation is foreseeable in the consumer stories where they openly write about their expenditure on drugs, alcohol, tobacco as well as their tendencies to steal and be addicted to gambling. This addictive behavior is distinctive in special circumstances (Godderis, 2006), but it also serves other functions than constructing a reflective consumer identity. Consuming snacks and food serves as identity maintenance (cf. Smith, 2002) rather than 
reflective identity work. Thus, the studied young people's consumer behavior is not only based on, as postmodern consumer theories suggest, identity construction (e.g. Featherstone, 1991, Giddens, 1991; Slater, 2003) where clothes, music, media products and services are important part of life.

Yet, these young people also practice identity work as consumers. They describe their consumerism to be like any other young person to involve spending, saving and regretting their purchases (Wilska, 2003; Autio, 2005; Gianneschi 2012). When they write about growing up from a wastrel to a prudent consumer, they position themselves into reflective agents. They also build up their consumer identity through goods and services valuable to them, such as games, make-up and hobbies. Despite their vulnerable life conditions these institutions provide a playground to create and practice reflective consumer behaviors just like their peers who live 'normalized' lives.

The studied young people also emphasize and appreciate brand clothing as well as their passion for quality and expensive goods. They learn about this culture of consumption (i.e. expensive items and brands, burning money) from their peers at school. Their behavior can be interpreted as striving towards mainstream consumption (Diversi, 2006; De Castro, 2006) and lifting up their marginal position in contemporary consumer culture. In this way they play out a position in society (Miles, 2000) and a relationship with consumer society and culture.

The young people had had destructive life styles before they came to the schools and they needed to adjust their behavior. They are disciplined to follow school rules and they describe the challenges to grow up as consumers, when the schools guide their behavior. Furthermore, at school they have a tendency to learn how consumer culture can be mobilized to show off their designer clothes etc. to their peers (Skattebol, 2011; Elliot \& Leonard, 2004). However, staying in a restrictive institution also provides them with management skills such as selfcontrol and planning the use of money, which meets the objectives of mainstream schooling's consumer education. Thus, they are growing up as consumers in the hybrid phase of earlier life experiences, school rules and practices and their free time.

\subsection{Narrative Method and Promoting Consumer Skills}

Using written narratives to obtain research material from young consumers appears to be productive and useful. It also seems to be a better way to gather data from young people in institutional settings than face-to-face interviews (Aaltonen \& Honkatukia, 2012), if researcher want to break the formal structure of an interview and to avoid reproducing relations of authority. Written narratives serve self-comprehension, and writing a story may help a young person to identify him/herself as an economic agent. It seems that stories also provide an arena to produce a positive self-image. The background factors of institutional life, problematic life situations and the perspective of these young people as just troublemakers faded from the narratives - at least partially. Furthermore, the stories of growing up to be a responsible consumer, or aiming to do so, demonstrate that these young consumers have the ability to control their spending.

After reform school, the economic resources offered by society do not lead to a life in luxury, upon which one could build a lifestyle based on branded clothing and luxury items. Thus, a young person's growth as a consumer is one challenge alongside many others, as they move towards an independent existence. However, as these consumer narratives suggest, the stories 
embrace personal growth and reflective thoughts on consumer behavior, sometimes even critiques, of their life choices and situations.

From an educational point of view (Bryderup, 2004), the question is, how the schools are able to serve these young people to regulate their behavior and to assist their reintegration (Trout \& Epstein, 2010) into society as they enter adulthood after school. Some young people may at least partially return to their lifestyles before reform school, and have difficulties in finding their place and life routine after the placement (Thompson et al., 2016). In addition, consumer society itself embraces this problematic situation. Consumer culture has become more and more seductive; in that kind of culture vulnerable individuals may be more at risk than their peers. As our study shows, these young people are just beginning to learn to cope with their autonomy over their choices. There is a need to create supporting services and mentoring for these young, vulnerable people in order to reintegrate them into society - as a consumers.

\section{References}

Aaltonen, S., \& Honkatukia, P. (2012). Interviewing young people in institutional contextsmethodological reflections. In T. Tolonen, T. Palmu, S. Lappalainen \& T. Kurki (Eds.), Cultural practices and transitions in education (pp. 34-47). London: Tufnell Press.

Autio, M. (2005). Morality of Spending in Finnish Youth Consumer Culture. International Journal of Consumer Studies, 29, 332-341.

Autio, M., Heiskanen, E., \& Heinonen, V. (2009). Narratives of 'Green' Consumers - the Antihero, the Environmental Hero and the Anarchist. Journal of Consumer Behaviour, 8, 40 53.

Barber, J., \& Delfabbro, P. (2005). Children's Adjustment to Long-Term Foster Care. Children and Youth Services Review, 27, 329-340.

Bourdieu, P. (1984[2010]). Distinction - A Social Critique of the Judgement of Taste. London \& New York: Routledge.

Bringewatt, E. H. (2013). Negotiating narratives surrounding children's mental health diagnoses: Children and their contribution to the discourse. Children and Youth Services Review, 35, 1219-1226.

Bryderup, I. M. (2004). The Educational Principles of Social Education and Special Education for Children and Youngsters in Care: A Danish Study. Young - Nordic Journal of Youth Research, 12, 337-356.

Campbell, C. (1987). The Romantic Ethic and the Spirit of Modern Consumerism. London: Blackwell.

Cunningham, M. J., \& Diversi, M. (2013). Aging out: Youths' perspectives on foster care and the transition to independence. Qualitative Social Work, 12, 587-602. 
Croghan, R., Griffin, C., Hunter, J., and Phoenix, A. (2006). Style Failure: Consumption, Identity and Social Exclusion. Journal of Youth Studies, 9, 463-478.

Czarniawska, B. (2006). Narratives in Social Science Research. London: Sage.

De Castro, L. R. (2006). What is new in the 'south'? Consumer culture and the vicissitudes of poor youth's identity construction in urban Brazil. Young - Nordic Journal of Youth Research, 14, 179-201.

Diversi, M. (2006). Street Kids in Nikes: In Search of Humanization Through the Culture of Consumption. Cultural Studies $<=>$ Critical Methodologies, 6, 370-390.

Douglas, M. (1966 [2002]). Purity and Danger: An Analysis of Concepts of Pollution and Taboo. New York: Routledge.

Elliott, R., \& Leonard, C. (2004). Peer pressure and poverty. Exploring fashion brands and consumption symbolism among children of the British poor. Journal of Consumer Behaviour, 3, 347-359.

Featherstone, M. (1991). Consumer Culture \& Postmodernism. Bristol: Sage Publications.

Fiates, G. M. R., Amboni, R. D. M.C., \& Teixeira, E. (2008). Consumer behaviour of Brazilian primary school students: findings from focus group interviews. International Journal of Consumer Studies, 32, 157-162.

Geiger, J. M., Hayes, M.J., \&. Lietz, C. A. (2014). Providing Foster Care for Adolescents: Barriers and Opportunities. Child \& Youth Services, 35 (3), 237-254.

Gianneschi, M. (2012). Vara och märkas - unga konsumenters relationer till klädindustrins varumärken [Dissertation]. Göteborg: Bokförlaget BAS.

Giddens, A. (1991). Modernity and Self-Identity: Self and Society in the Late Modern Age. Cambridge: Polity Press.

Gilbert, E. (2007). Constructing 'Fashionable' Youth Identities: Australian Young Women Cigarette Smokers. Journal of Youth Studies, 10, 1-15.

Godderis, R. (2006). Dining in: The symbolic power of food in prison. The Howard Journal, 45, 255-267.

Hyde, J., \& Kammerer, N. (2009). Adolescents' perspectives on placement moves and congregate settings: Complex and cumulative instabilities in out-of-home care. Children \& Youth Services Review, 31, 265-273.

Jahnukainen, M. (2007). High-risk youth transitions to adulthood: A longitudinal view of youth leaving the residential education in Finland. Children and Youth Services Review, 29, 637-654.

Jones, L., \& Lansdverk, J. (2006). Residential education: Examining a new approach for improving outcomes for foster youth. Children and Youth Services Review, 28, 1152-1168. 
Lundby, E. (2012). If you have money, you can be kinder to them, possessions and economic resources in children's peer groups. Young Consumers: Insight and Ideas for Responsible Marketers, 13, 136-146.

McCrystal, P., Percy, A., \& Higgins, K. (2007). Exclusion and Marginalisation in Adolescence: The Experience of School Exclusion on Drug Use and Antisocial Behaviour. Journal of Youth Studies, 10, 35-54.

Miles, S. (2000). Youth Lifestyles in a Changing World. Buckingham: Open University Press.

Miles, S., Cliff, D., \& Burr, V. (1998). 'Fitting In and Sticking Out': Consumption, Consumer Meanings and the Construction of Young People's Identities. Journal of Youth Studies, 1, 8196.

Moisander, J., \& Valtonen, A. (2006). Qualitative Marketing Research: A Cultural Approach. London: Sage Publications.

Nayak, A. (2006). Displaced Masculinities: Chavs, Youth and Class in the Post-industrial City. Sociology, 40, 813-831.

Nayak, A., \& Kehily, M. J. (2013). Gender, youth and culture: Young masculinities and femininities. Palgrave Macmillan.

Nybell, L. M. (2013). Locating "youth voice:" Considering the contexts of speaking in foster care. Children and Youth Services Review, 35, 1227-1235.

Reith, G. (2004). Consumption and its discontents: addiction, identity and the problems of freedom. British Journal of Sociology, 55, 283-300.

Ridge, T. (2011). The everyday costs of poverty in childhood: a review of qualitative research exploring the lives and experiences of low-income children in the UK. Children \& Society, 25, 73-84.

Simmel, G. 1900[1982)]. The philosophy of money [Die philosophie des Geldes] (translated by Tom Bottomore and David Frisby). Boston, Mass.: Routledge.

Skattebol, J. (2011). "When the money's low": Economic participation among disadvantaged young Australians. Children and Youth Services Review, 33, 528-533.

Slater, D. (2003). Consumer Culture \& Modernity. Cambridge: Polity Press.

Smith, C. (2002). Punishment and Pleasure: Women, Food and the Imprisoned Body. Sociological Review, 50, 197-214.

Terpstra, J. (2006). Youth Subculture and Social Exclusion. Young - Nordic Journal of Youth Research, 14, 83-99. 
Thompson, A. E., Greeson, J.K.P., \& Brunsink, A. M. (2016). Natural mentoring among older youth in and aging out of foster care: A systematic review. Children and Youth Services Review, $61,40-50$.

Trout, A.L., \& Epstein, M. H. (2010). Developing aftercare: Phase I: Consumer feedback. Children and Youth Services Review, 32, 445-451.

Vehkalahti, K. (2003). Portraits of Delinquency and Penitence: Telling Life-Stories in a Reform School Context. History of Education Researcher, 71, 14-27.

Wilska, T-A (2003). Mobile Phone Use as Part of Young People's Consumption Styles. Journal of Consumer Policy, 26, 441-463. 